\title{
28. MAGNETIC PROPERTIES OF A VOLCANIC-RICH SEDIMENTARY SEQUENCE IN THE INTRA-ARC AOBA BASIN ${ }^{1}$
}

\author{
Pierrick Roperch, ${ }^{2}$ Thierry Chabernaud,${ }^{3}$ and Françoise Calza ${ }^{4}$
}

\begin{abstract}
Ocean Drilling Program (ODP) Sites 832 and 833 were drilled in the intra-arc North Aoba Basin of the New Hebrides Island Arc (Vanuatu). High volcanic influxes in the intra-arc basin sediment resulting from erosion of volcanic rocks from nearby islands and from volcanic activity are associated with characteristic magnetic signals. The high magnetic susceptibility in the sediment (varying on average from 0.005 to more than $0.03 \mathrm{SI}$ ) is one of the most characteristic physical properties of this sedimentary depositional environment because of the high concentration of magnetites in redeposited ash flows and in coarse-grained turbidites.

Susceptibility data correlate well with the high resolution electrical resistivity logs recorded by the formation microscanner (FMS) tool. Unlike the standard geophysical logs, which have low vertical resolution and therefore smooth the record of the sedimentary process, the FMS and whole-core susceptibility data provide a clearer picture of turbiditic sediment deposition.

Measurements of Curie temperatures and low-temperature susceptibility behavior indicate that the principal magnetic minerals in ash beds, silt, and volcanic sandstone are Ti-poor titanomagnetite, whereas Ti-rich titanomagnetites are found in the intrusive sills at the bottom of Site 833. Apart from an increase in the concentration of magnetite in the sandstone layer, acquisition of isothermal and anhysteretic remanences does not show significant differences between sandstone and clayey silts. The determination of the anisotropy of magnetic susceptibility (AMS) in more than 400 samples show that clayey siltstone have a magnetic anisotropy up to $15 \%$, whereas the AMS is much reduced in sandstone layers. The magnetic susceptibility fabric is dominated by the foliation plane, which is coplanar to the bedding plane. Reorientations of the samples using characteristic remanent magnetizations indicate that the bedding planes dip about $10^{\circ}$ toward the east, in agreement with results from FMS images.

Basaltic sills drilled at Site 833 have high magnetic susceptibilities ( 0.05 to $0.1 \mathrm{SI})$ and strong remanent magnetizations. Magnetic field anomalies up to $50 \mu \mathrm{T}$ were measured in the sills by the general purpose inclinometer tool (GPIT). The direction of the in-situ magnetic anomaly vectors, calculated from the GPIT, is oriented toward the southeast with shallow inclinations which suggests that the sill intruded during a reversed polarity period.
\end{abstract}

\section{INTRODUCTION}

Two sites were drilled during Ocean Drilling Program (ODP) Leg 134 in the intra-arc North Aoba Basin to investigate the volcano-tectonic evolution of the central New Hebrides Island Arc. Site 832 is located in the center of the North Aoba Basin in a water depth of 3089 $\mathrm{m}$ and about $45 \mathrm{~km}$ south and $50 \mathrm{~km}$ north of the active volcanoes of Santa Maria Island and Aoba Island, respectively (Fig. 1). Site 832 is also located at about $50 \mathrm{~km}$ from the northern tip of Espiritu Santo and Maewo islands. Site 833 is located approximately $24 \mathrm{~km}$ northwest from Maewo Island and about $70 \mathrm{~km}$ southeast of Santa Maria Island.

Deep holes were drilled at Site 832 and Site 833, with penetration of $1107 \mathrm{~m}$ and $1001 \mathrm{~m}$. Core recovery was good; recovery averaged about $50 \%$. The most common sediment types are ashfall deposits, hemipelagic silt and clay, turbidites, and debris flows. The high volcanogenic content of most sedimentary lithostratigraphic units produces prominent magnetic susceptibility signals. A detailed investigation of magnetic properties in black mud turbidites in the distal Bengal fan (ODP Leg 116) made by Sager and Hall (1990) demonstrated that this type of sedimentation process produces magnetic signatures with distinctive susceptibility peaks, caused by variations in concentration of titanomagnetite grains by a factor of about 10 . In addition, Pezard et al. (1992) have shown that high resolution FMS images from drillholes in the Izu-Bonin forearc basin (ODP Leg 126) provide a detailed description of turbidite sequences.

The purpose of this paper is to present the observed magnetic characteristics (magnetic susceptibility, composition, and grain size

\footnotetext{
${ }^{1}$ Greene, H.G., Collot, J.-Y., Stokking, L.B., et al., 1994. Proc. ODP, Sci. Results, 134: College Station, TX (Ocean Drilling Program).

${ }^{2}$ ORSTOM, BP 48, 06230 Villefranche-sur-Mer, France.

${ }^{3}$ Lamont-Doherty Earth Observatory, Borehole Research Group, Columbia University, Palisades, New York 10964, U.S.A

${ }^{4}$ Laboratoire de Géophysique, Université de Rennes I, 35042 Rennes, France.
}

of magnetic minerals) in a volcanic-rich sedimentary environment. The magnetic signature of turbidites and debris flows produced by active volcanism at Aoba and Santa Maria islands, and erosion from surrounding uplifted Espiritu Santo and Maewo islands is compared with the FMS images.

\section{METHODS}

Whole-core magnetic susceptibility was measured aboard the Joides Resolution using a Bartington magnetic susceptibility meter with an $80-\mathrm{mm}$ sensor loop at a frequency of $0.47 \mathrm{kHz}$. Although the accuracy of measurements is affected by voids, particularly in liquefied sandy beds, recording of data at a spacing of $2.5 \mathrm{~cm}$ provides a large data base (more than 20,000 readings at each site) from which high-frequency variations and clear trends can easily be identified.

Discrete samples were taken for magnetostratigraphic studies (see Zhao et al., this volume). Seven- $\mathrm{cm}^{3}$ plastic boxes were taken in unconsolidated sediment recovered by advanced hydraulic piston coring (APC), whereas standard minicores ( 1 in. diameter, $2.2 \mathrm{~cm}$ long) were drilled in consolidated materials recovered by rotary drilling.

Studies of magnetic properties of samples from Sites 832 and 833 include artificial remanences, thermomagnetic experiments, lowtemperature susceptibility behavior and magnetic fabric determinations. Results are presented in the following sections.

\section{Anisotropy of Magnetic Susceptibility}

The anisotropy of magnetic susceptibility (AMS) has been determined for 491 minicore samples from Hole 833B. Most measurements were made using a Digico spinner anisotropy meter; a few measurements were obtained using the high-sensitivity Czech susceptibility bridge KLY-2. Four hundred eight samples were reoriented using the characteristic remanent magnetization. Mean normalized tensors with $95 \%$ confidence ellipses were calculated following the 


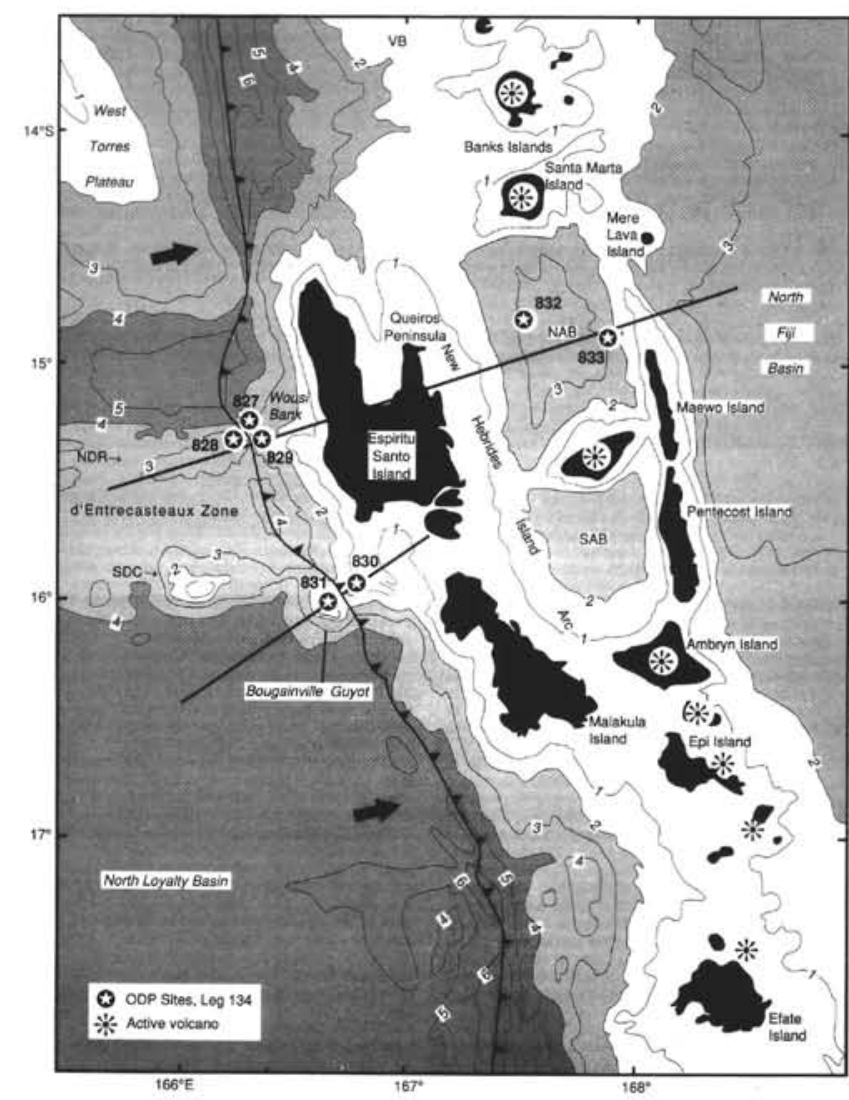

Figure 1. Location map of the Leg 134 Sites 832 and 833 in the North Aoba Basin. Bathymetry in kilometers. Line with teeth indicates plate boundaries; arrows indicate direction of plate movement.

Jelinek (1978) method, which provides a satisfactory description of the errors in AMS data (Lienert, 1991).

\section{Thermomagnetic Analyses and Curie Temperatures}

Thermomagnetic behaviors were investigated with a vertical Curie balance at the University of Rennes using 10 to $100 \mathrm{mg}$ of materials heated in air or in vacuum. To reduce the importance of the loss of weight resulting from dewatering upon heating, some experiments in air were carried out on slightly enriched sediment using a hand magnet.

\section{Low-temperature Susceptibility Behavior}

The behavior of magnetic susceptibility from liquid nitrogen temperature $(78 \mathrm{~K})$ to room temperature in basaltic rocks has been summarized by Senanayake and McElhinny (1981). Upon cooling in liquid nitrogen, the magnetic susceptibility decreases to about $20 \%$ of its room temperature value for Ti-rich titanomagnetite, whereas multidomain magnetites exhibit a slight increase in suceptibility with a kink near the isotropic point temperature $(130 \mathrm{~K})$ when the sign of the magnetocrystalline constant $K$ changes from negative to positive. Thus, low-temperature susceptibility behavior is a non-destructive method that provides information about the magnetic mineralogy.

\section{Artificial Remanences}

The acquisition and the demagnetization behavior of isothermal remanent magnetization (IRM) and anhysteretic remanent magnetization (ARM) permit characterization of the magnetic mineralogy (composition and microstructure) (Lowrie and Fuller, 1971; Stacey and Banerjee, 1974). Crossplots of magnetic susceptibilities and arti- ficial remanences are often used for a quick evaluation of grain size and concentration of magnetite in sediment (King et al., 1982; Bloemendal et al., 1992).

Acquisition of saturation IRM was studied using a Brucker electromagnet in a progressively increasing field up to $1.2 \mathrm{~T}$. ARM was acquired in a direct current (DC) field of $45 \mu \mathrm{T}$ with a peak alternating field of $100 \mathrm{mT}$, which is the maximum value of the Schonstedt AF demagnetizer. Results of IRM acquisition demonstrate that titanomagnetite is the principal magnetic carrier; saturation fields are less than $200 \mathrm{mT}$ and about $90 \%$ of the saturation remanence was acquired by $100 \mathrm{mT}$. Thus, the maximum AF field value available in this study is near the saturation field. ARM magnetizations were imparted to 165 samples and IRM magnetizations were given to 42 samples.

\section{MAGNETIC SUSCEPTIBILITY RECORDS}

At both Sites 832 and 833 , the average magnetic susceptibility level is usually high, above 0.005 SI with susceptibility peaks up to 0.05 SI. Variations in the magnetic susceptibility records (Fig. 2) in volcanogenic sediment at both Sites 832 and 833 in the North Aoba Basin reflect the lithostratigraphic units assigned by shipboard sedimentologists (see Collot, Greene, Stokking, et al., 1992, and Goud Collins, this volume). For example, the volcanic breccias corresponding to lithostratigraphic Unit IV at Site 832 are easily identified in the susceptibility record and easily distinguished from the underlying Unit V, composed of calcareous siltstone.

On the other hand, contrasts in the susceptibility records at sites 832 and 833 indicate differences in the sedimentation processes and sediment sources. For example, lithostratigraphic Unit V at Site 832 was correlated with Unit IV at Site 833 (see Collot, Greene, Stokking, et al., 1992, and Goud Collins, this volume). However, magnetic susceptibility of Unit IV at Site 833 is higher than that of Unit V at Site 832 and this difference demonstrates that the volcanic input in the sediment is much higher at Site 833 than at Site 832. The difference in volcanic content is also correlated to a much higher sedimentation rate for Unit IV at Site 833 (about $10 \mathrm{~cm} / \mathrm{k}$.y.) than for Unit V at Site 832 (about $2 \mathrm{~cm} / \mathrm{k} . \mathrm{y}$.) (see Staerker, this volume, and Zhao et al., this volume).

Very low magnetic susceptibility was encountered in volcanic breccias at the bottom of Site 832, especially below 1050 meters below seafloor (mbsf). These breccias were described as the product of submarine volcanism because their matrixes contain abundant alteration products, such as palagonite, chlorite, clay minerals, and zeolite. The contrast in magnetic susceptibility is particularly marked with breccias from Unit IV. Further investigations are needed to understand the difference in behavior of the very low magnetic susceptibility breccias at the base of the hole and the highly magnetic breccias of Unit IV.

In an attempt to describe the relationship between the magnetic susceptibility and the sedimentary record, we will first discuss the relative contribution of ash and silt in the uppermost $40 \mathrm{~m}$ of sediments at both sites. We will then compare the magnetic susceptibility data with other physical properties recorded downhole.

\section{Magnetic Susceptibility Records in the Uppermost 40 Meters}

The comparison of the susceptibility records is limited to the upper $40 \mathrm{~m}$ of sediment in lithostratigraphic Unit I at both sites (Fig. 3) because liquefied sandy beds constitute the major lithology below 40 $\mathrm{m}$ and resulted in incomplete filling of APC cores. Sites 832 and 833 are almost at equal distances from the active volcanoes of Santa Maria and Aoba, which are the expected sources of volcanic ashes. Thus, the deposition of vitric materials at both sites, if originating from ashfall deposits, should correlate between susceptibility records for both sites unless trade winds affected sediment deposition.

The principal characteristics of the susceptibility records are a downhole increase of the susceptibility and the presence of welldefined susceptibility peaks at Site 833 that are not observed at Site 
Site 832

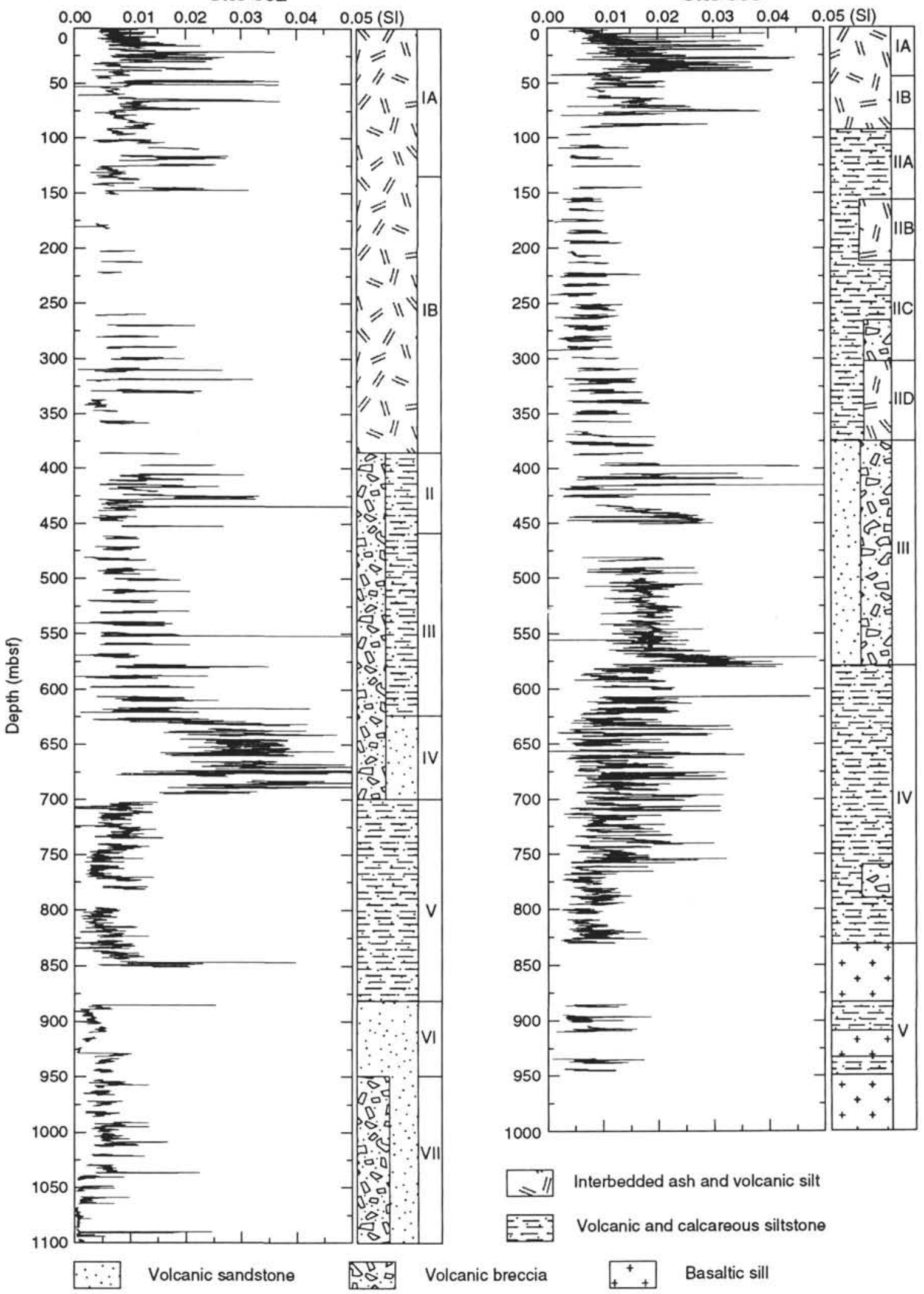

Figure 2. Comparison of the whole-core magnetic susceptibility records in sediment at Sites 832 and 833 in the intra-arc North Aoba Basin. The simplified lithology and the associated lithostratigraphic units are from Collot, Greene, Stokking, et al. (1992) and Goud Collins (this volume). 

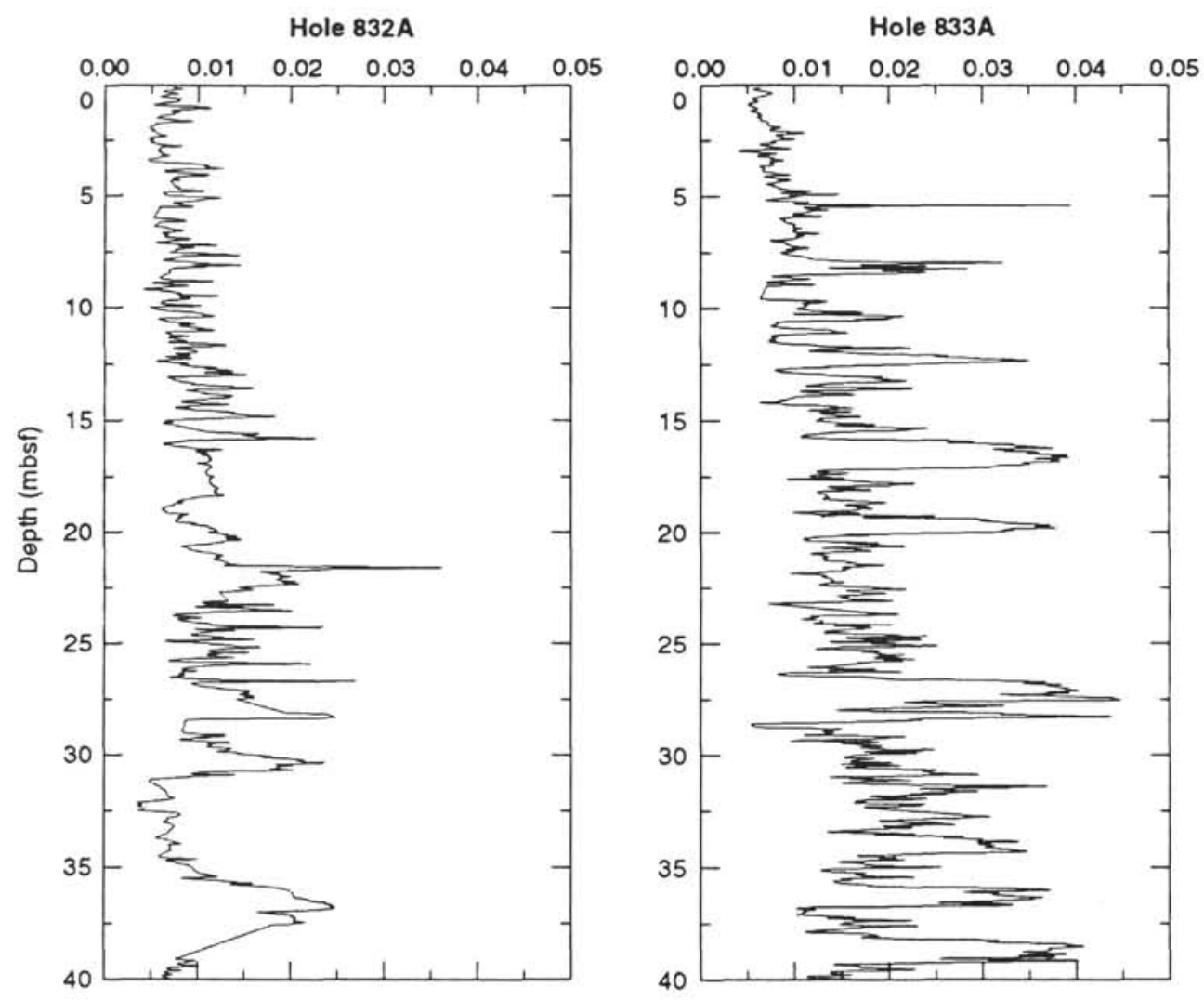

Figure 3. Comparison of the magnetic susceptibility records (in SI units) in the upper 40-m sedimentary sequence at both Holes $832 \mathrm{~A}$ and $833 \mathrm{~A}$. There is no obvious correlation between the two basin sites.

832. The differences between the susceptibility profiles is explained by a larger contribution of volcanic-rich sediment derived from Maewo Island at Site 833 than at Site 832 . The high proportion of volcanic silt and sand with high susceptibility prevents the correlation of ash beds in the magnetic susceptibility data from Site 832 and 833.

\section{Comparison of Magnetic Susceptibility with Electrical Resistivity at Site $\mathbf{8 3 3}$}

Density and sonic velocity were measured on whole-core samples in undisturbed APC cores, but no measurement was attempted on rotary cores. Thus, a comparison of the whole-core susceptibility data was made with standard in-situ geophysical logging measurements. The incomplete core recovery and the resulting unconstrained depth assignment unfortunately make crossplots difficult to perform. However, despite the resulting poor depth correlation, it was obvious that the large susceptibility changes associated with major lithologic variations were also reflected in logs. Crossplots of electrical resistivity with magnetic susceptibility exhibited the most significant correlation (Fig. 4). Calcareous volcanic siltstone and claystone have low magnetic susceptibilities and low electrical resistivities, whereas volcanic sandstones and breccias have high susceptibilities and electrical resistivities. This correlation has led us to compare the whole-core susceptibility with the high-resolution Formation MicroScanner (FMS) electrical images. Indeed, in standard logs, data are recorded every 6 in., and the logging tools have a large volume of investigation that significantly reduces the vertical resolution. In contrast, the FMS resistivity pads slide on the borehole wall and the vertical resolution is at a centimeter scale. The FMS electrical conductivity record is compared to the susceptibility in the depth interval 640-760 mbsf at Site 833 (Fig. 5). The lithology corresponds to interbedded volcanic calcareous siltstone and sandstone. Both types of record (susceptibility and FMS) clearly image the sedimentation process. Several turbiditic sequences from 1 to $10 \mathrm{~m}$ thick are identified by their sharp base contrasts in susceptibility and electrical resistivity. The fining upward trend is indicated by the regular decrease in resistivity and susceptibility. Intervals with higher frequency, for example between 675 and 680 mbsf, are also observed on both records. In a previous study of volcaniclastic sediment drilled during Leg 126 on the Izu-Bonin Arc (Holes 792E and 793B, Pezard et al., 1992), the high-resolution FMS images were used to analyze the depositional processes and bedthickness trends and frequencies of turbidites. Pezard et al. (1992) concluded that the sequence of turbidites was randomly distributed and that the bed thicknesses are distributed according to a power law with a characteristic exponent of 1.0. The magnetic susceptibility record from Site 793B (Leg 126, Taylor, Fujioka, et al., 1990) shows (as at Site 833 ) peak-to-peak variations with magnetic susceptibility varying from 0.01 to 0.03 SI. There are strong similarities in FMS images and magnetic susceptibility records between the Izu-Bonin (Leg 126) and the Vanuatu (Leg 134) volcanoclastic sedimentary sequences. However, a detailed statistical analysis of the sedimentary sequences in the North Aoba Basin is still needed before conclusions reached by Pezard et al. (1992) could be applied for the North Aoba Basin.

Figure 6 illustrates the resolution of the different logging tools compared to the whole-core measurements of magnetic susceptibility. The major oxides derived from the geochemical data do not reflect the magnetic susceptibility changes because of a poor statistical accuracy obtained by only one pass. High gamma-ray values are correlated to minima in resistivity and susceptibility that is explained by an increase in clay content. Sonic transit times, and to a lesser extent density, are well correlated to the magnetic susceptibility since volcanic sandstones have high susceptibilities, higher densities, and higher sonic velocities. However, the vertical resolution of Schlumberger logs is less than that of the whole-core measurements and FMS. 


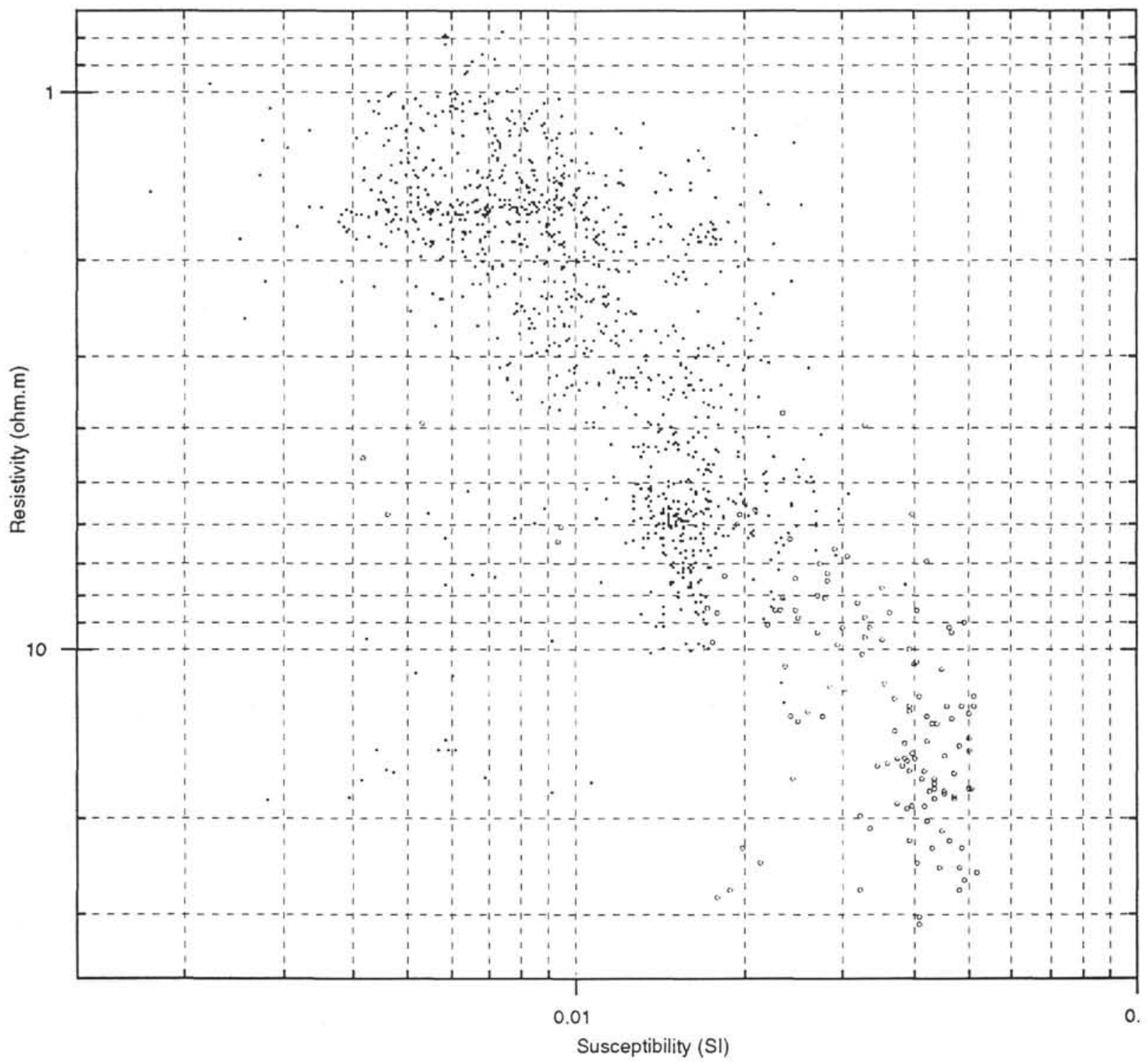

Figure 4. Correlation of susceptibility data (measured on whole cores) with downhole resistivity data. Despite a dispersion mainly due to inaccuracy in depth, there is a general correlation that demonstrates that the sandstone layers have higher resistivity than calcareous-rich clayey silt. Data from volcaniclastic sediment are shown in black dots and data from basaltic sills are in open circles.

A susceptibility tool would provide high-resolution lithological data set that could complement the textural information revealed by the FMS. Thus, there is an obvious interest in developing a magnetic susceptibility logging tool similar to the FMS.

\section{MAGNETIC PROPERTIES}

\section{Thermomagnetic Experiments}

Thirty-four samples from Sites 832 and 833 were studied. Typical results are illustrated in Figures 7 and 8.

All thermomagnetic experiments attempted on volcanic ashes produced the same types of behavior (Fig. 7). Upon heating, there is a more or less pronounced inflection on the heating curve near $350^{\circ} \mathrm{C}$ that could indicate the presence of maghemite due to low temperature oxidation. The principal Curie temperature is slightly above $500^{\circ} \mathrm{C}$ and titanomagnetite with Curie point above $500^{\circ} \mathrm{C}$ is also the only magnetic phase observed upon cooling.

Examples of thermomagnetic curves observed in volcanic silt are shown on Figure 8. Although the loss of weight approaches $10 \%$ for experiments performed on whole-rock (Samples 134-833A-2H-7, $50-51 \mathrm{~cm}$, and $-3 \mathrm{H}-7,21-22 \mathrm{~cm}$ ), similar thermomagnetic behavior is observed in the magnetically enriched materials (Sample 134-833A$5 \mathrm{H}-1,93-94 \mathrm{~cm})$. The thermomagnetic behaviors of samples in the volcanic silts are very similar to those observed in the ash beds.

Thermomagnetic experiments in the Pliocene volcanic sandstone and siltstone also reveal a magnetic phase (titanomagnetite) with a Curie temperature near $500^{\circ} \mathrm{C}$ (Fig. 8). The shape of the cooling curve is dependent on the maximum temperature reached and whether the experiments were conducted in air or in vacuum. However, all experiments indicated a single magnetic phase upon cooling with a Curie temperature slightly above $500^{\circ} \mathrm{C}$.

The thermomagnetic experiments in the basaltic sills reveal that titanomagnetite with Curie temperatures above $300^{\circ} \mathrm{C}$ is the principal magnetic mineral. The few Curie temperatures available suggest that higher Curie temperatures are observed in the lowermost sills (Fig. 8). The experiment performed in air (Sample 134-833B-85R-3, $45-46 \mathrm{~cm}$ ) shows irreversibility above $350^{\circ} \mathrm{C}$, which suggests the inversion of titanomaghemite during heating (O'Reilly, 1984). 

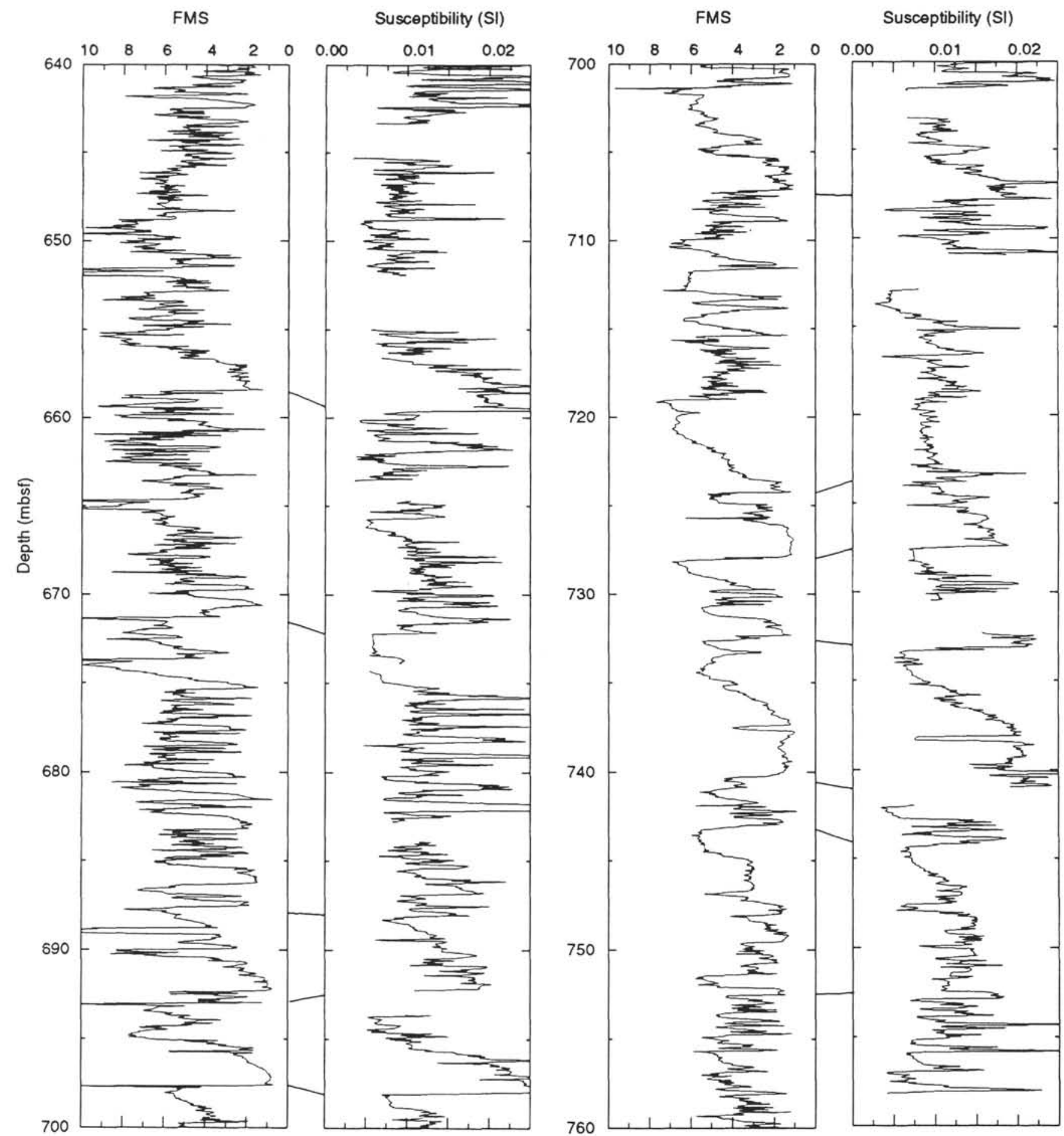

Figure 5. Correlation of electrical conductivity data from the FMS pads (in instrument units) with magnetic susceptibility measured on whole cores. Sharp bases and fining upward turbiditic sequences are recognized on both plots.

\section{Low-temperature Susceptibility Variations}

Variations in magnetic susceptibility with temperature from liquid nitrogen to room temperature are shown on Figure 9 for two groups of samples. The magnetic susceptibility at liquid nitrogen temperature is about $20 \%$ of the room temperature susceptibility for samples from the basaltic sills while the ratio is $80 \%$ for samples from siltstone and sandstone. Ti-rich titanomagnetites are the predominant magnetite carriers in the basaltic sills while Ti-poor titanomagnetites are found in the vol- canic siltstone and sandstone. The low temperature experiments are in agreement with observations from thermomagnetic experiments.

\section{Artificial Remanences}

Progressive acquisition of IRM was performed on various samples from siltstone and sandstone. They all indicate saturation fields below $0.2 \mathrm{~T}$, which demonstrate that goethite or hematite are not part of the magnetic mineralogy (Fig. 10). The shape of progressive ARM de- 


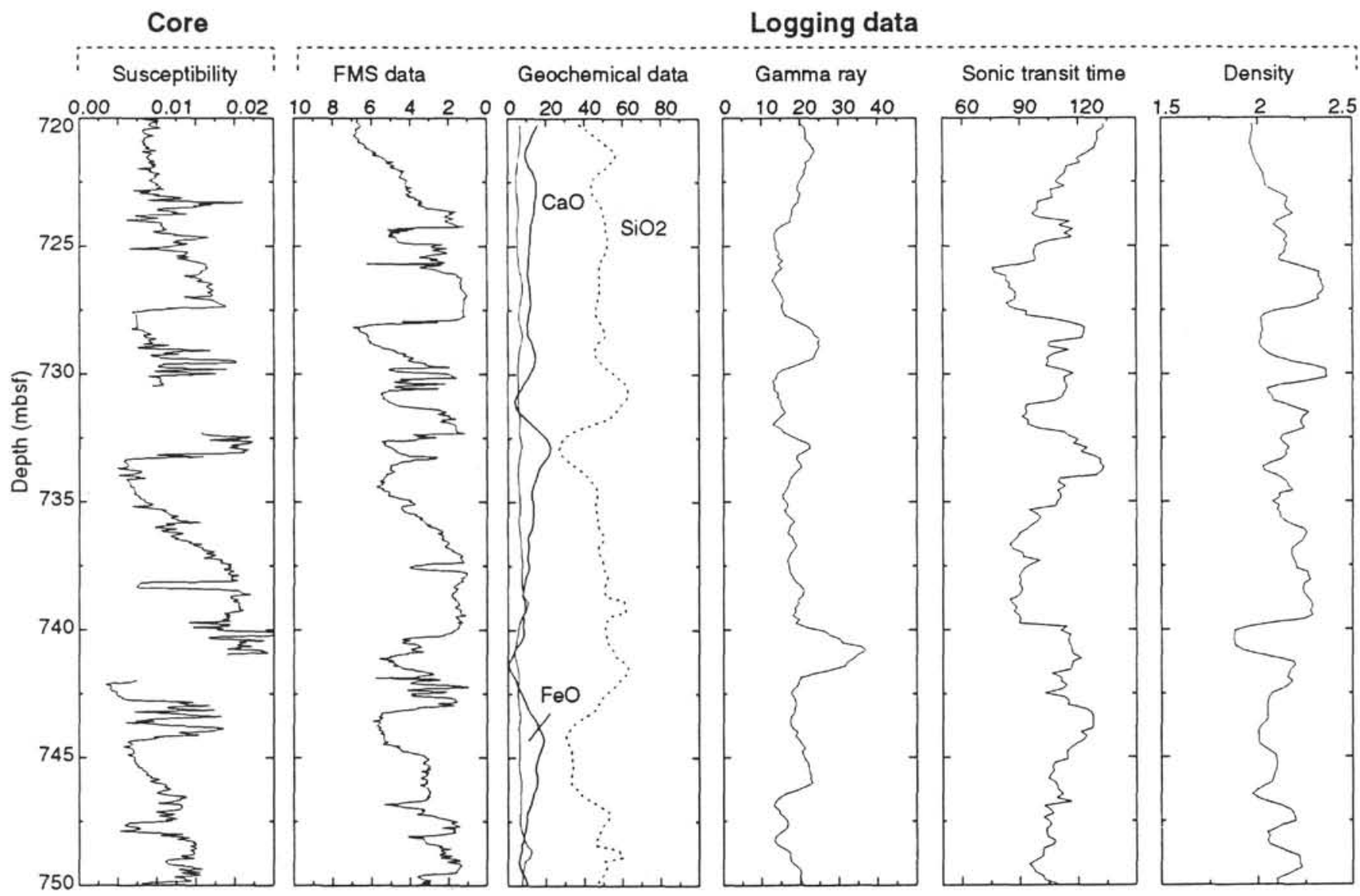

Figure 6. Vertical resolution of standard logging data (geochemical, gamma ray [API units], sonic [ $\mu \mathrm{s} / \mathrm{ft}]$, and density $\left[\mathrm{g} / \mathrm{cm}^{3}\right]$ ) compared to downhole FMS data and whole-core susceptibility data.

magnetization curve was surprisingly consistent between sandstone and siltstone indicating that there are no large variations in magnetic grain size between the sandstone and siltstone (Fig. 10). The medium destructive field (MDF) of ARM was near $25 \mathrm{mT}$, whereas the MDF of IRM in siltstone and sandstone samples was scattered between 10 and $20 \mathrm{mT}$ (Fig. 11). This behavior indicates a bimodal distribution of magnetic particle sizes with the presence of pseudo-single-domain (PSD) to multidomain (MD) magnetites that dominate high-field remanences and also finer magnetic grains of single domain (SD) to PSD type, which have a larger influence on weak-field remanences (Dunlop, 1973). In contrast, the low MDF values $(<10 \mathrm{mT})$ for most samples in the basaltic sills (Fig. 11) indicate a larger grain size with possibly multidomain titanomagnetite.

Another approach to the study of magnetic grain sizes and concentration of magnetic minerals is the use of crossplots of ARM, IRM, and susceptibility. Figure 12 shows the distribution of magnetic susceptibility $(K)$ versus ARM susceptibility $\left(K_{\text {arm }}\right)$; both are dimensionless in SI units. For magnetite and titanomagnetite, $K$ and $K_{a r m}$ are dependent on the concentration and domain state of magnetic minerals. $K_{a r m}$ increases with decreasing grain size while $K$ increases with grain size (King et al., 1982), except in very fine superparamagnetic grains below the SD state. Ratios of $K_{a r m} / K$ vary from 1 to 10 suggesting that most of the magnetic carriers are in the PSD to MD range.

The distribution of data from the sediment samples indicates a slight decrease in grain size for the most calcareous samples (lowest $K$ ). In contrast, there is a clear difference between the different sills drilled at the bottom of Hole 833B. Samples from the upper sill have larger $K_{\text {arm }} / K$ ratios than samples from the underlying sills, indicating that the largest grains are in the lower sill units. This observation is in agreement with the instability of the natural remanence (see Zhao et al., this volume).

\section{Anisotropy of Magnetic Susceptibility}

AMS in natural rocks is controlled mainly by shape alignment of magnetic grains and lattice alignment of crystals with magnetocrystalline anisotropy (see Hrouda [1982] for a review of magnetic anisotropy of rocks and its application in geology and geophysics). Although the AMS does not yield an unambiguous determination of particle alignment because shape anisotropy is different in multidomain and single-domain magnetite grains (Potter and Stephenson, 1988), measurement of AMS is a quick, nondestructive method for determination of a petrologic or sedimentary fabric. In sedimentary rocks, the preferred orientation of magnetic minerals is controlled by bottom currents and compaction.

The low-induction magnetic susceptibility anisotropy of a rock is described as a symmetric tensor of second rank; it can be represented graphically as an ellipsoid with principal axes maximum $K\left(K_{\max }\right)$, intermediate $K\left(K_{i n t}\right)$, and minimum $K\left(K_{\min }\right)$. When $K_{\text {int }}$ is closer to $K_{\max }$ than $K_{\min }$, the ellipsoid takes an oblate shape and the magnetic fabric defines a foliation. In the other case when $K_{\text {int }}$ is closer to $K_{\min }$, the ellipsoid is prolate with a magnetic lineation. The degree of anisotropy is defined by $\mathrm{P}=K_{\max } / K_{\min }$, and following Ellwood et al. (1988), the lineation is defined by $K_{\max } / K_{\text {int }}$ and the foliation by $K_{\text {int }} / K_{\min }$.

Variation of the lineation and foliation parameters with depth at Site 833 is shown on Figure 13. The lineation parameter is usually low $(<1.02)$ except for a few samples in the depth interval 750-825 mbsf. Increase in the foliation parameters (up to 1.15) correlates with 

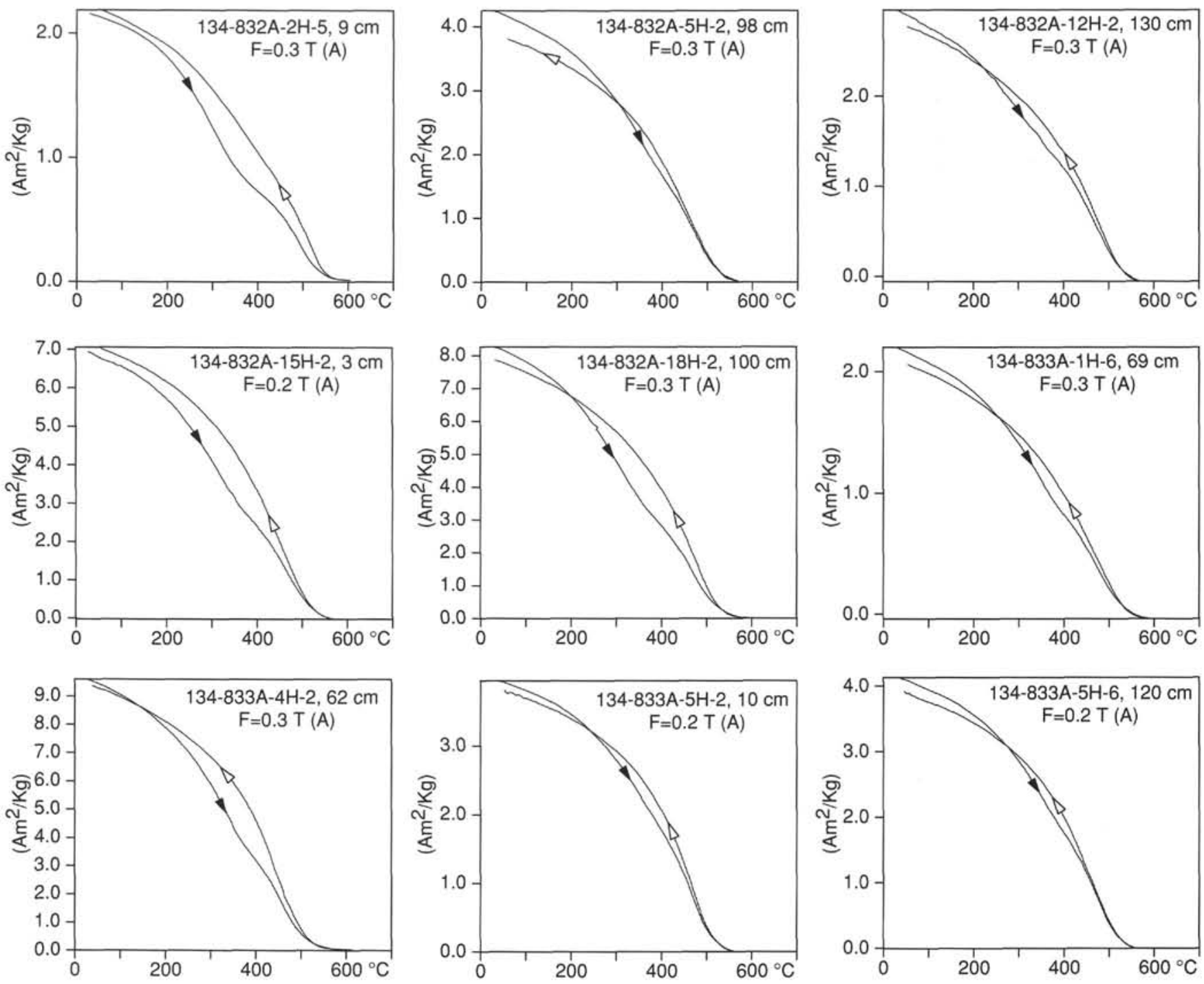

Figure 7. Examples of strong field thermomagnetic behaviors in samples from volcanic ash beds. $F$ is the magnetic field value in teslas. (A), (V) indicates whether the experiments were performed in air (A) or in vacuum (V).

a decrease in susceptibility, indicating a lower anisotropy in sandstone layers than in calcareous claystone and siltstone layers. For example, samples from sandstone and breccias in lithostratigraphic Unit III have a less marked anisotropy than those from the underlying Unit IV. The magnetic anisotropy in the basaltic sills (characterized by their high magnetic susceptibility) is low.

All minicore samples were taken from unoriented drill core pieces. Since all samples were previously used for magnetostratigraphic purposes, the direction of the remanent magnetization can be used to reorient the samples. Equal-area projections of mean tensorial directions with associated ellipses of confidence are shown on Figure 14 and results are summarized in Table 1. Mean normalized tensors were calculated for the main lithostratigraphic Units II and III. Lithostratigraphic Unit IV for which numerous data are available was divided in four groups. A mean tensor was also calculated for samples from sediment layers of lithostratigraphic Unit V. The mean results are very consistent and all show an oblate shape fabric with a minimum magnetic susceptibility axis colinear with the pole of the bedding plane indicating a bedding attitude dipping $10^{\circ}$ toward the west. The mean degree of anisotropy (Table 1 ) is $5 \%$ to $6 \%$ in sediment from Core $134-833 \mathrm{~B}-60 \mathrm{R}$ to the bottom of the hole, whereas the mean anisotropy degree is about half that value in lithostratigraphic Unit II.
The lowest anisotropy degree is found in the sandstone from Unit III. The difference in behavior between sandstone layers and calcareous siltstone indicates that magnetite grains are attached to clay minerals. The slight increase of anisotropy with depth suggests that the magnetic fabric not only results from an initial depositional fabric but may have been enhanced by compaction.

As previously mentioned, increases in lineation values are observed near 800 mbsf. The magnetic fabrics for nine samples from Core 134-833B-77R define a tightly grouped horizontal maximum susceptibility axis (Fig. 15). Observations of cores suggest slumping and we interpret the direction of maximum anisotropy as a direction orthogonal to the slumping direction.

Measurements on basaltic sills could only be used for the uppermost basaltic sills because no paleomagnetic direction is available for the bottom sills. Sixteen samples from Cores 134-833B-81R, -82R, and $-83 R$ show a mean magnetic fabric with a vertical minimum axis and and east-west trending maximum susceptibility. A speculative interpretation of this lineation direction is that it indicates an almost east-west flow direction of emplacement of the sill. In reorienting the magnetic fabrics, we have assumed that the shallow paleomagnetic direction was characteristic of a reverse polarity magnetization (see Zhao et al., this volume). This interpretation is further supported by 

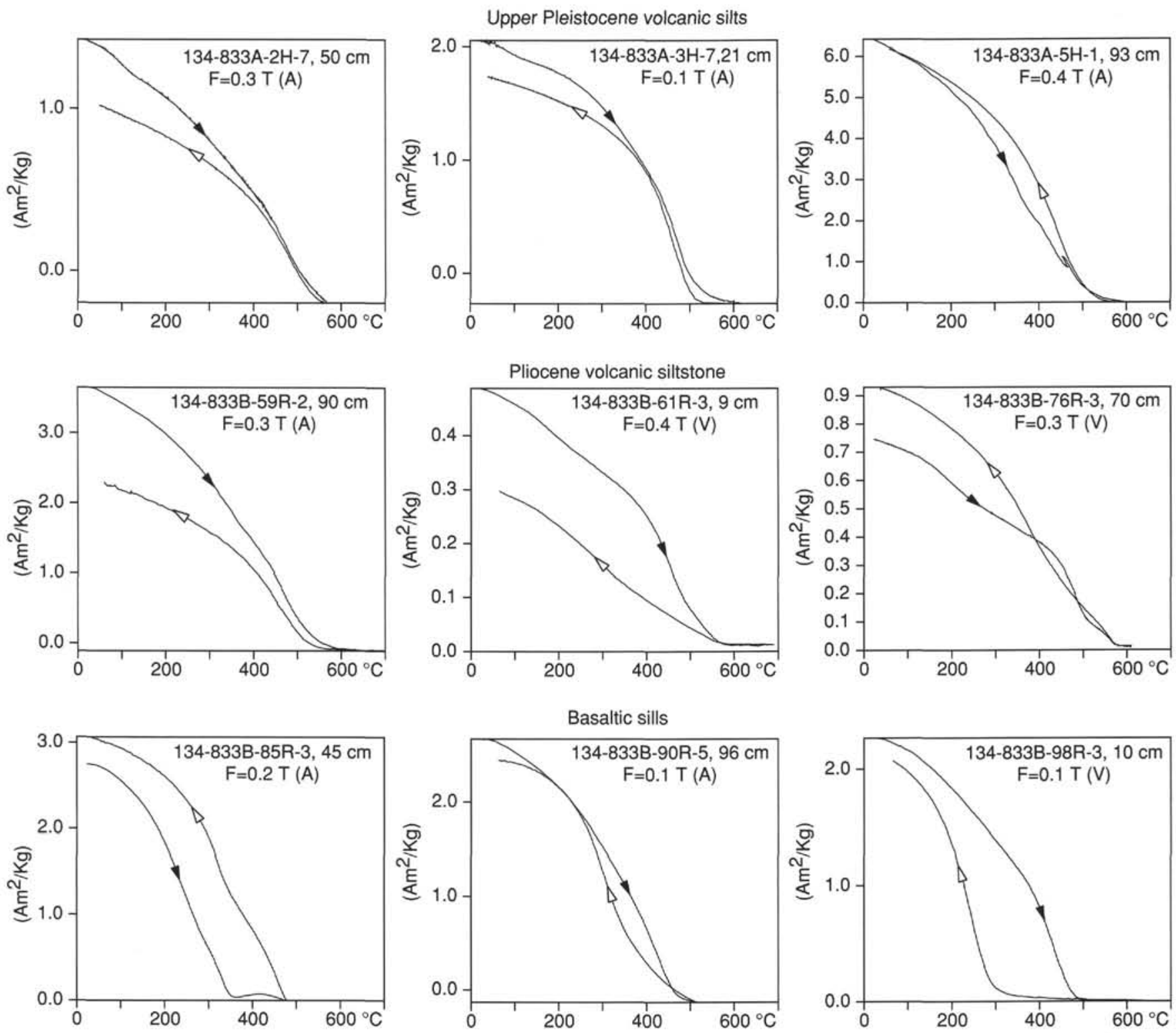

Figure 8. Examples of strong field thermomagnetic behaviors in volcanic silt, siltstone, and basaltic sills. Same conventions as in Figure 7.

the interpretation of magnetic field anomalies measured downhole (see below).

It should be noted that using the primary magnetization implies that the samples are oriented with a mean paleomagnetic field that could be different from the present geographic axis. FMS images were obtained in Hole 833B (FMS data are oriented with a downhole magnetometer, and the International Geomagnetic Reference Field is automatically used to provide a geographic reference). Thus, the comparison of geological structures such as bedding planes and fractures determined from FMS images and visually observed structures from cores provides a mean to orient the cores in the geographic reference frame. Analysis of paleomagnetic data (Falvey, 1978) and seafloor spreading in the North Fiji Basin indicate that clockwise rotation of about $30^{\circ}$ of the New Hebrides Island Arc occurred from 8 to $3 \mathrm{Ma}$ (Auzende et al., 1988). Thus, the residual rotation that occurred since the middle Pliocene is reduced and the paleomagnetic field should not differ much from the present-day geographic axis. Directions of geological structures such as bedding planes and fractures determined from FMS images and visually observed structures from cores reoriented using the same paleomagnetic database are very similar, but the scatter in the data prevents a detailed analysis (Pelletier et al., this volume). We have attempted a statistical comparison of the FMS data with the AMS data in the depth interval (625-770 mbsf) where the FMS and AMS data are of good quality. Moreover, sediments in this depth interval were deposited between 4 to $3 \mathrm{Ma}$ and a difference between the FMS oriented structures and the paleomagnetically oriented AMS data would provide information on the timing of the rotation of the New Hebrides Island Arc. The results are summarized in Table 2 and Figure 16. There is a significant difference between FMS and AMS mean data if the hole deviation is not taken into account (Fig. 16). Although the hole deviation $\left(3.4^{\circ}\right.$ to $\left.\mathrm{N} 339^{\circ}\right)$ was small in the considered depth interval (Fig. 17), the comparison of FMS and AMS data shows however the positive effect of taking into account the hole deviation. As a standard procedure, FMS data are automatically corrected for hole deviation while AMS data cannot be corrected since we do not know the true declination respective to the azimuth of the hole. Instead of correcting AMS data, the FMS data were corrected back to the hole position. This reversed correction to the FMS data demonstrates that there is no statistical difference between the geographic reference frame (FMS) and the paleomagnetic reference frame. Thus, 
Table 1. Anisotropy of magnetic susceptibility parameters, Hole 833B.

\begin{tabular}{|c|c|c|c|c|c|c|c|c|c|c|c|c|c|}
\hline Core & $N$ & $K_{\max }$ & D & I & $K_{i n t}$ & D & I & $K_{\min }$ & D & I & $\begin{array}{c}K_{\max } \\
K_{i n t} \\
\end{array}$ & $\begin{array}{l}K_{\text {in }} \\
K_{\min }\end{array}$ & $\begin{array}{l}\text { An } \\
(\%)\end{array}$ \\
\hline \multicolumn{14}{|l|}{$134-833 \mathrm{~B}-$} \\
\hline IR-31R & 57 & 1.008 & 165.0 & 0.0 & 1.007 & 75.0 & -10.4 & 0.985 & 75.0 & 79.6 & 1.000 & 1.023 & 2.3 \\
\hline $32 \mathrm{R}-54 \mathrm{R}$ & 75 & 1.004 & 151.5 & 0.0 & 1.004 & 61.5 & -9.4 & 0.992 & 61.5 & 80.6 & 1.000 & 1.012 & 1.2 \\
\hline $55 \mathrm{R}-59 \mathrm{R}$ & 32 & 1.009 & 275.1 & 8.7 & 1.005 & 185.2 & -0.8 & 0.986 & 100.6 & 81.3 & 1.003 & 1.020 & 2.3 \\
\hline $60 R-64 R$ & 47 & 1.016 & 347.4 & 3.6 & 1.012 & 256.6 & 12.7 & 0.971 & 93.2 & 76.8 & 1.004 & 1.043 & 4.7 \\
\hline $65 R-69 R$ & 32 & 1.021 & 326.1 & 7.3 & 1.016 & 235.0 & 8.6 & 0.963 & 96.0 & 78.7 & 1.004 & 1.055 & 6.0 \\
\hline $70 R-74 R$ & 43 & 1.017 & 334.0 & 5.0 & 1.015 & 243.0 & 11.4 & 0.968 & 87.4 & 77.5 & 1.003 & 1.048 & 5.1 \\
\hline $75 \mathrm{R}-81 \mathrm{R}$ & 58 & 1.016 & 34.5 & -7.8 & 1.011 & 305.2 & 4.7 & 0.973 & 66.2 & 80.9 & 1.006 & 1.039 & 4.5 \\
\hline $81 \mathrm{R}-83 \mathrm{R}^{*}$ & 16 & 1.007 & 89.1 & 1.1 & 0.998 & 179.0 & -6.6 & 0.994 & 8.7 & -83.3 & 1.009 & 1.004 & 1.3 \\
\hline $89 \mathrm{R}-94 \mathrm{R} * *$ & 25 & 1.024 & 354.5 & 1.9 & 1.015 & 264.0 & 16.4 & 0.961 & 90.8 & 73.5 & 1.009 & 1.055 & 6.5 \\
\hline
\end{tabular}

Notes: $\%=$ number of samples used to determine the mean normalized susceptibility tensor; $K_{\max }, K_{i n r^{\prime}}$ and $K_{\min }$ are the eigenvalues with their respective eigenvectors; $\mathrm{D}=$ declination, $\mathrm{I}=$ inclination in paleomagnetic coordinates; $\% \mathrm{An}=$ $\left(\left(K_{\max } / K_{\min }\right)-1\right) \times 100$. An asterisk $\left(^{*}\right)=$ Samples from basaltic sills; a double asterisk $\left(^{* *}\right)=$ samples from sediments interlayered with the sills.

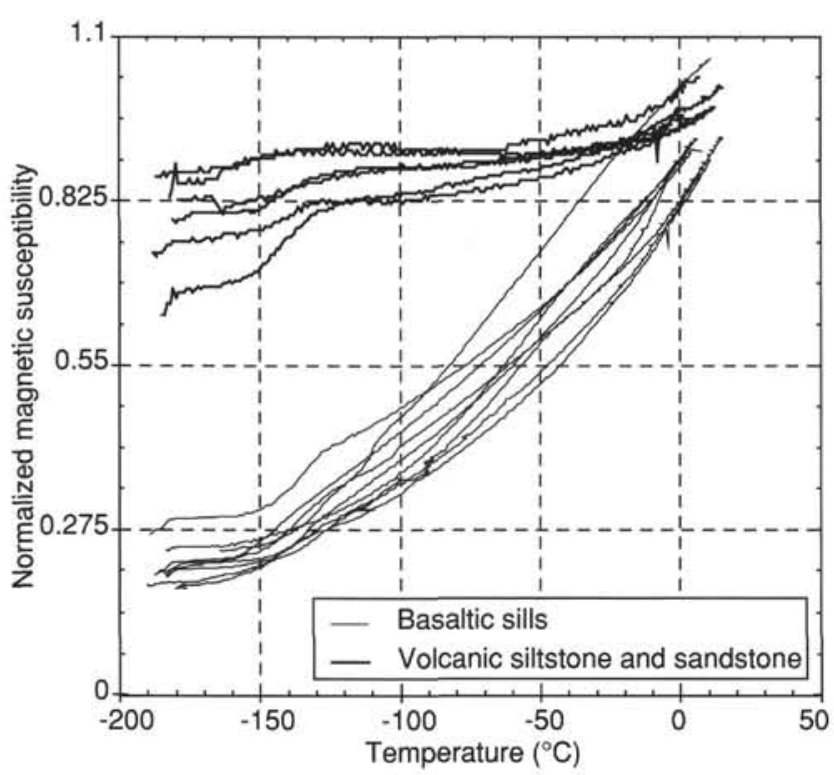

Figure 9. Low-temperature variations of the low-field magnetic susceptibility in sediment and basaltic sills from liquid nitrogen temperature up to room temperature.

our AMS data show that no significant rotation of the New Hebrides Island Arc occurred since the middle Pliocene.

The determination of AMS in samples from which the remanent magnetization is retrieved has several advantages on structural measurements made on cores: reorientations of the structures derived from AMS are straightforward, and AMS can detect structures that cannot be recognized by an observer.

\section{INTERPRETATION OF MAGNETIC FIELD ANOMALY IN BASALTIC SILLS}

The determination of in-situ magnetic parameters using magnetic logging in oceanic crust has been attempted a few times in DSDP (Ponomarev and Nechoroshkov, 1983, 1984) and ODP (Bosum and Scott, 1988; Kinoshita et al., 1989; Pariso et al., 1991). Development of magnetic logging in sediments is in progress (Pocachard et al., 1991) and magnetic logging experiments in the carbonate cap of the Bougainville Guyot are described in Roperch et al. (this volume). During the FMS logging operation in Hole 833B, very large magnetic field anomalies were recorded.

The FMS tool uses three directional magnetometers and a general purpose inclinometer tool (GPIT) to orient FMS resistivity images.
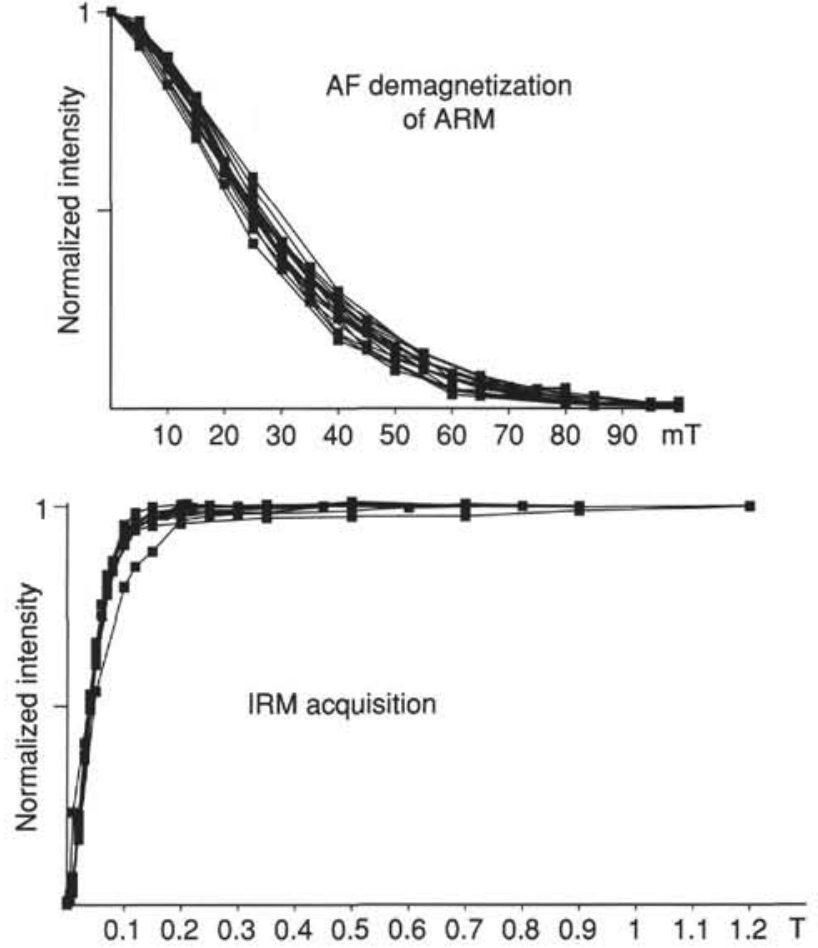

Figure 10. AF demagnetization of ARM and acquisition of IRM in silt and sandstone.

Figure 16 illustrates the characteristic parameters recorded downhole in the depth interval 600 to 930 mbsf. The hole deviation increases slightly from about $3^{\circ}$ to $4^{\circ}$. The hole azimuth increases slowly downhole from about $\mathrm{N} 330^{\circ}$ to $350^{\circ}$ except from 830 to $885 \mathrm{mbsf}$ where large variations are observed. The total magnetic field and the magnetic field inclination are also strongly perturbed within the sills. The strong natural remanent magnetizations up to $100 \mathrm{~A} / \mathrm{m}$ reported by Zhao et al. (this volume) and the ARM susceptibility of about 0.5 (Fig. 12) demonstrate that the magnetic anomalies recorded downhole mostly reflect the strong remanent magnetizations.

It is important to remember that the GPIT is not oriented gyroscopically and only the vertical is defined by the inclinometer tool. To circumvent this problem, we made a basic assumption about the trend of the hole azimuth. As can be seen on Figure 17, the hole azimuth determined above and below the sill is almost constant. Although the hole deviation is not large, we speculate that changes in the hole azimuth within the sill are not real but result from magnetic 
Table 2. Comparison of FMS mean pole of bedding with AMS $K_{\min }$ direction, Hole 833B.

\begin{tabular}{lrrrrc}
\hline & $N$ & D & I & $K$ & $\alpha 95$ \\
\hline FMS $(625-770 \mathrm{~m}):$ & 1255 & 71.2 & 77.0 & 95 & 0.4 \\
$\left(^{*}\right)$ corrected: & 122 & 85.5 & 76.4 & & \\
AMS Cores $(60 \mathrm{R}-74 \mathrm{R}):$ & & 78.1 & 31 & 2.3 \\
\hline
\end{tabular}

Notes: $\mathrm{N}=$ number of samples used to determine the mean direction, $\mathrm{D}=$ declination of the mean pole of bedding for FMS data and AMS $K_{\min }$ direction, $\mathrm{I}=$ inclination of mean direction, $K=$ precision parameter for the Fisher statistics, $\alpha 95=$ angle of confidence at $95 \%,(*)=$ the FMS mean pole was reverse corrected for hole deviation using a mean deviation of $3.4^{\circ}$ as the azimuth of $339^{\circ}$ in order to provide a direct comparison with AMS data.
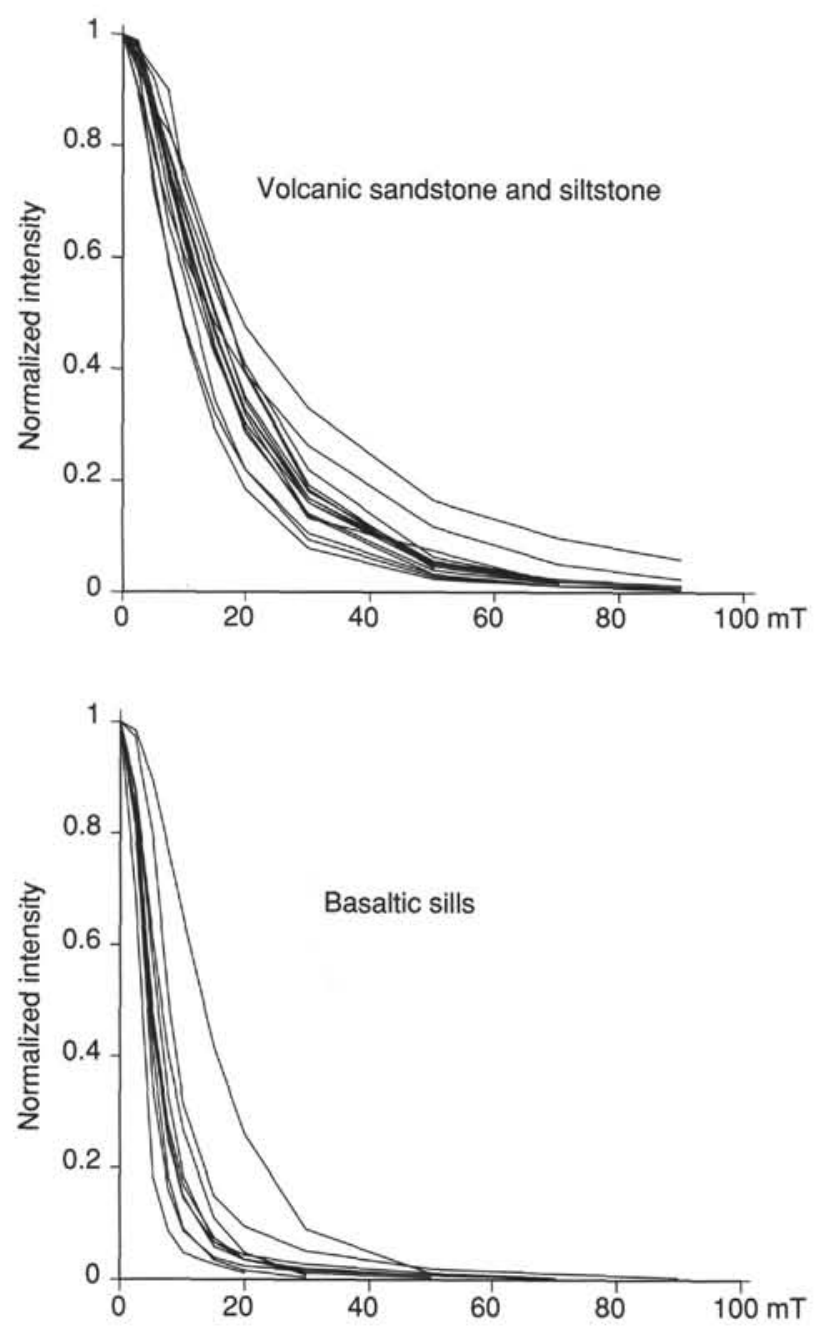

Figure 11. AF demagnetization of IRM in sediment and basaltic sills.

declination anomalies created by the remanent magnetizations. This assumption enables us to reorient the magnetometer. By removing the estimated geomagnetic field using the International Geomagnetic Reference Field (IGRF 1985; declination: $-11.5^{\circ}$, inclination: $-37.8^{\circ}$, $\mathrm{F}: 43700 \mathrm{nT}$ ), we can calculate the magnetic field anomaly in the borehole (Fig. 18).

Although the magnetic susceptibility was high, the contribution of the induced magnetization is not as important as the contribution from the remanent magnetization. The magnetic anomaly profile (Fig. 18)

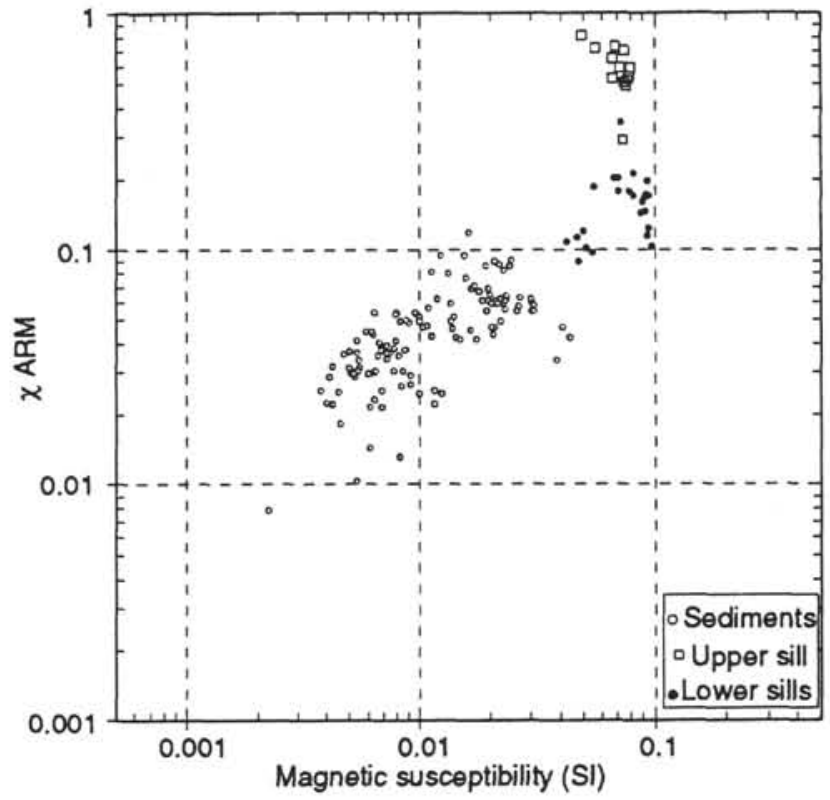

Figure 12. Crossplot of ARM susceptibility vs. magnetic susceptibility.

indicates remanent magnetization vectors with south-southeast declination and shallow inclination, suggesting the intrusion of the sill during a reversed period. However, the strong correlation between the calculated magnetic anomaly profile and the hole azimuth may indicate that the hypothesis used to orient the magnetometer is too strong.

The GPIT is not designed to obtain information about the in-situ magnetization. A magnetometer oriented with a gyroscope and regularly cross-calibrated sensors with an accuracy of $1 \mathrm{nT}$ is required for the effective use of this tool in moderately magnetized oceanic rocks $(1 \mathrm{~A} / \mathrm{m})$. On the other hand, magnetic anomalies in highly magnetic rocks such as pillow lavas can lead to significant errors in the orientation of FMS images.

\section{CONCLUSION}

In studying sediment accumulation in an intra-arc basin, we have shown that the magnetic susceptibility variations closely reflect the lithological variations. Correlation of magnetic susceptibility wholecore profiles with downhole FMS resistivity records demonstrate the potential information that can be provided by a high-resolution magnetic susceptibility logging tool.

Magnetic characteristics such as artificial remanences and Curie points indicate that the magnetic minerals in the volcanogenic sediment at Site 832 and 833 are low-Ti titanomagnetite in pseudo-single domain state. In contrast, in the basaltic sills at Site 833, the magnetic minerals are titanomagnetites with Curie points in the temperature range $300-450^{\circ} \mathrm{C}$. Larger magnetic grain sizes in samples from the sills below $900 \mathrm{mbsf}$ than those in samples from the upper sill suggests either. a different mode of intrusion or a different magma source. The latter is in better agreement with petrologic information (see Collot, Greene, Stokking, et al., 1992).

The anisotropy of magnetic susceptibility corresponds to an oblate magnetic fabric dominated by sediment deposition and compaction. The fabric is less marked in sandstone layers than in the calcareous siltstone. After reorientating the AMS data using the remanent magnetizations, the foliation plane is tilted toward the west. The comparison of AMS data and FMS images demonstrates that no significant clockwise tectonic rotation of the New Hebrides Island Arc has occurred since middle Pliocene. 


\section{ACKNOWLEDGMENT}

We would like to thank the ODP technical staff who made all measurements of whole-core magnetic susceptibility.

\section{REFERENCES*}

Auzende, J.-M., Lafoy, Y., and Marsset, B., 1988. Recent geodynamic evolution of the north Fiji Basin (southwest Pacific). Geology, 16:925-929.

Bloemendal, J., King, J.W., Hall, F.R., and Doh, S.-J., 1992. Rock magnetism of late Neogene and Pleistocene deep-sea sediments: relationship to sediment source, diagenetic process, and sediment lithology. J. Geophys. Res., 97:4361-4375.

Bosum, W., and Scott, J.H., 1988. Interpretation of magnetic logs in basalt, Hole 418A. In Salisbury, M.H., Scott, J.H., et al., Proc. ODP, Sci. Results, 102: College Station, TX (Ocean Drilling Program), 77-95.

Collot, J.-Y., Greene, H.G., Stokking, L.B., et al., 1992. Proc. ODP, Init. Repts., 134: College Station, TX (Ocean Drilling Program).

Dunlop, D.J., 1973. Superparamagnetic and single-domain threshold sizes in magnetite. J. Geophys. Res., 78:1780-1793.

Ellwood, B.B., Hrouda, F., and Wagner, J.-J., 1988. Symposia on magnetic fabrics: introductory comments. Phys. Earth Planet. Inter., 51:249-252.

Falvey, D.A., 1978. Analysis of paleomagnetic data from the New Hebrides. Australas. Soc. Explor. Geophys. Bull., 9:117-123.

Hrouda, F., 1982. Magnetic anisotropy of rocks and its application in geology and geophysics. Geophys. Surv., 5:37-82.

Jelinek, V., 1978. Statistical processing of anisotropy of magnetic susceptibility measured on group of specimens. Stud. Geophys. Geod., 22:50-63.

King, J.W., Banerjee, S.K., Marvin, J., and Özdemir, Ö., 1982. A comparison of different magnetic methods for determining the relative grain size of magnetite in natural materials: some results from lake sediments. Earth Planet. Sci. Lett., 59:404-419.

Kinoshita, H., Furuta, T., and Pariso, J., 1989. Downhole magnetic field measurements and paleomagnetism, Hole 504B, Costa Rica Ridge. In Becker, K., Sakai, H., et al., Proc. ODP, Sci. Results, 111: College Station, TX (Ocean Drilling Program), 147-156.

Lienert, B.R., 1991. Monte Carlo simulation of errors in the anisotropy of magnetic susceptibility: a second-rank symmetric tensor. J. Geophys. Res., 96:19539-19544.

Lowrie, W., and Fuller, M., 1971. On the alternating field demagnetization characteristics of multidomain thermoremanent magnetization in magnetite. J. Geophys. Res., 76:6339-6349.

O'Reilly, W., 1984. Rock and Mineral Magnetism: New York (Blackie, Chapman and Hall).
Pariso, J.E., Scott, J.H., Kikawa, E., and Johnson, H.P., 1991. A magnetic logging study of Hole 735B gabbros at the Southwest Indian Ridge. In Von Herzen, R.P., Robinson, P.T., et al., Proc. ODP, Sci. Results, 118: College Station, TX (Ocean Drilling Program), 309-322.

Pezard, P.A., Hiscott, R.N., Lovell, M.A., Collela, A., and Malinverno, A., 1992. Evolution of the Izu-Bonin intraoceanic forearc basin, western Pacific, from cores and FMS images. In Hurst, A., Griffiths, C.M., and Worthington, P.F. (Eds.), Geological Applications of Wireline Logs II. Geol. Soc. Spec. Publ., London, 65:43-69.

Pocachard, J., Thomas, T., Barthès, V., Pagès, G., 1991. High resolution logging tool for borehole measurements of magnetization. IUGG, XX Assembly, Vienna.

Ponomarev, V.N., and Nechoroshkov, V.L., 1983. First measurements of the magnetic field within the ocean crust: Deep Sea Drilling Project Legs 68 and 69. In Cann, J.R., Langseth, M.G., Honnorez, J., Von Herzen, R.P., White, S.M., et al., Init. Repts. DSDP, 69: Washington (U.S. Govt. Printing Office), 271-279.

, 1984. Downhole magnetic measurements in oceanic crustal Hole 395A on the Mid-Atlantic Ridge. In Hyndman, R.D., Salisbury, M.H., et al., Init. Repts. DSDP, 78 (Pt. B): Washington (U.S. Govt. Printing Office), 731-739.

Potter, D.K., and Stephenson, A., 1988. Single-domain particles in rocks and magnetic fabric analysis. Geophys. Res. Lett., 15:1097-1100.

Sager, W.W., and Hall, S.A., 1990. Magnetic properties of black mud turbidites from ODP Leg 116, Distal Bengal Fan, Indian Ocean. In Cochran, J.R., Stow, D.A.V., et al., Proc. ODP, Sci. Results, 116: College Station, TX (Ocean Drilling Program), 317-336.

Senanayake, W.E., and McElhinny, M.W., 1981. Hysteresis and susceptibility characteristics of magnetite and titanomagnetites: interpretation of results from basaltic rocks. Phys. Earth Planet. Inter., 26:47-55.

Stacey, F.D., and Banerjee, S.K., 1974. Developments in Solid Earth Geophysics (Vol. 5): The Physical Principles of Rock Magnetism: Elsevier (New York).

Taylor, B., Fujioka, K., et al., 1990. Proc. ODP, Init. Repts., 126: College Station, TX (Ocean Drilling Program).

Abbreviations for names of organizations and publications in ODP reference lists follow the style given in Chemical Abstracts Service Source Index (published by American Chemical Society).

Date of initial receipt: 2 July 1992

Date of acceptance: 27 May 1993

Ms 134SR-027 

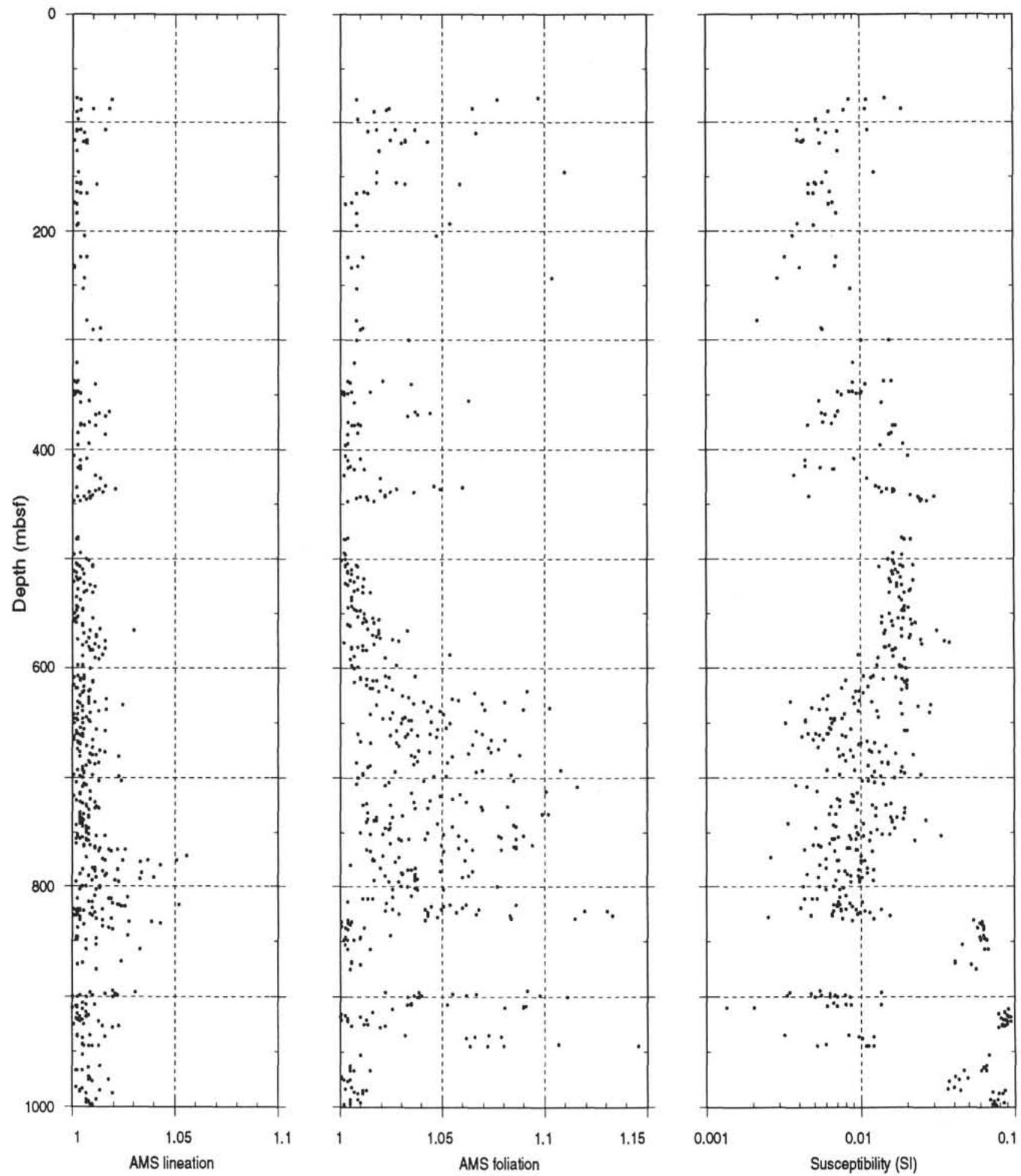

Figure 13. Plots of the anisotropy of magnetic susceptibility parameters against depth. 

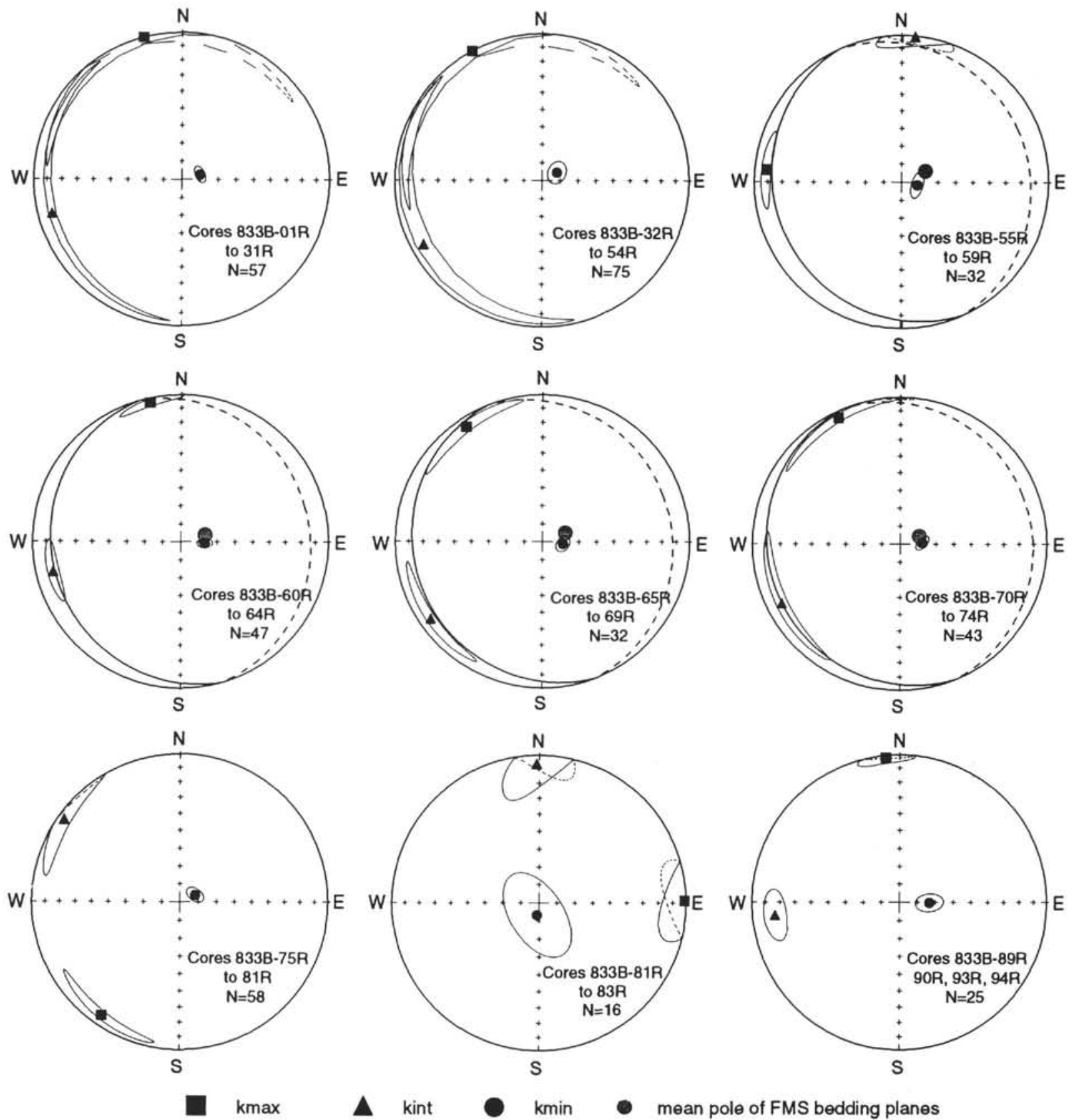

Figure 14. Equal-area plots of mean normalized principal susceptibility directions with their ellipses of $95 \%$ confidence (Jelinek, 1978) for different depth intervals in Hole 833B. Squares $=$ maximum axis; triangles $=$ intermediate axis; circles $=$ minimum axis. All samples used for the calculation of tensorial means were oriented with respect to the declination of the remanent magnetization. 


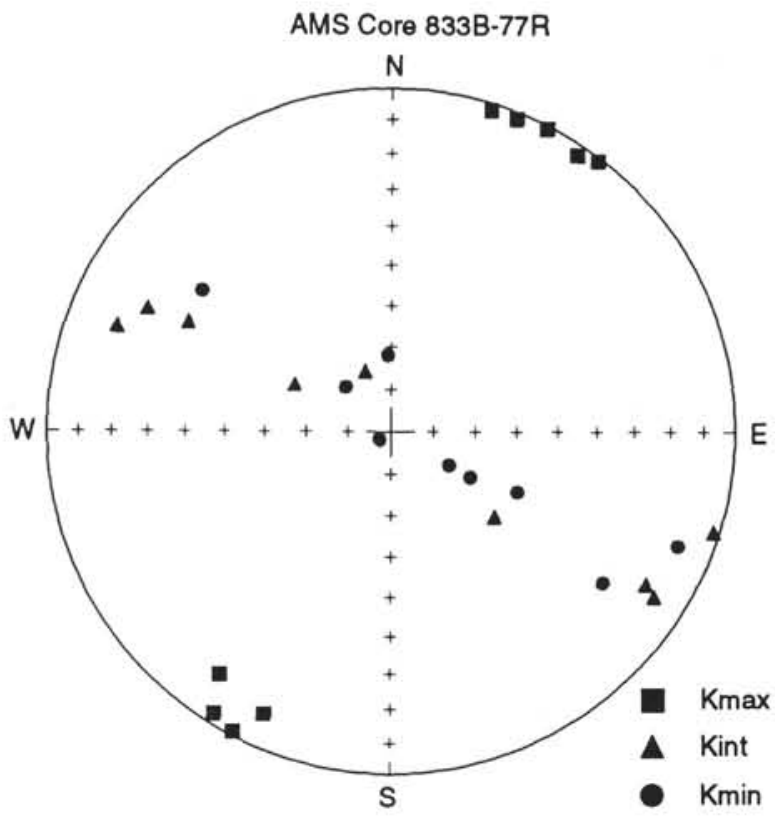

Figure 15. Equal-area plot of principal susceptibility directions in samples from Core 134-833B-77R for which the anisotropy fabric is slightly prolate with a well defined maximum anisotropy axis. Same conventions as in Figure 14.

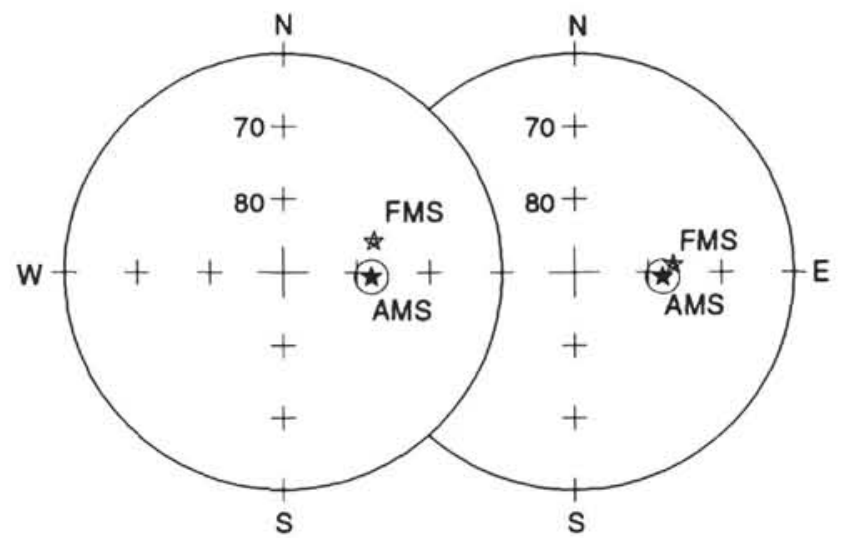

Figure 16. Enlarged equal-area plot of mean FMS pole of bedding (open star) and mean of AMS $K_{\min }$ direction (filled star) with associated angle of confidence at $95 \%$. Left: FMS in in-situ coordinates; right: FMS with a reversed correction for hole deviation. 


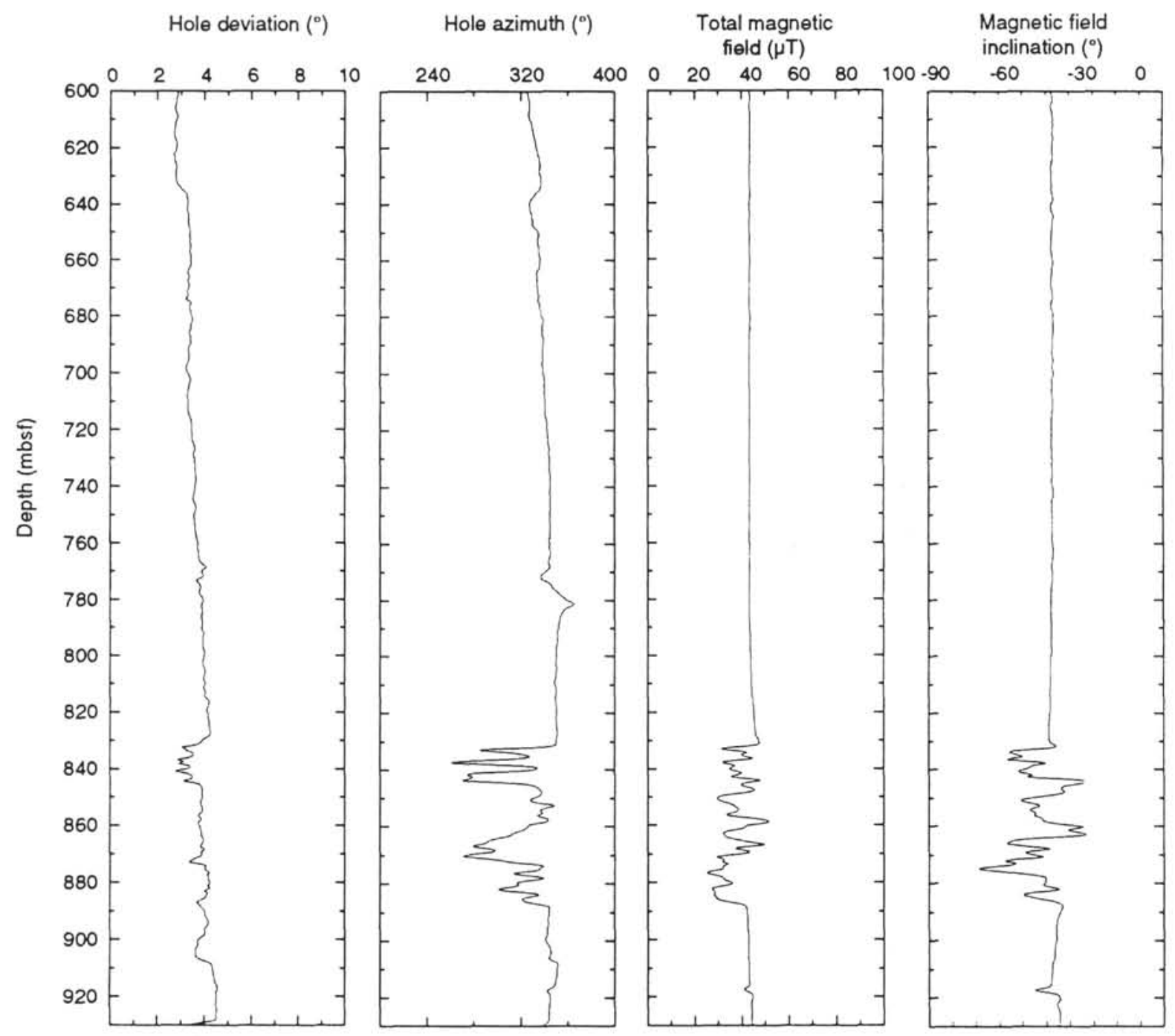

Figure 17. Hole drift parameters and magnetic data from the general purpose inclinometer tool (GPIT) in Hole 833B. Note the large magnetic anomalies in the basaltic sill from 830 to 885 mbsf. The azimuth of the hole is almost the same above and below the sill suggesting that the changes in hole azimuth within the sills are due to large anomalies of the magnetic declinations. The azimuth of the hole above the sill was used to reorient the GPIT data. 


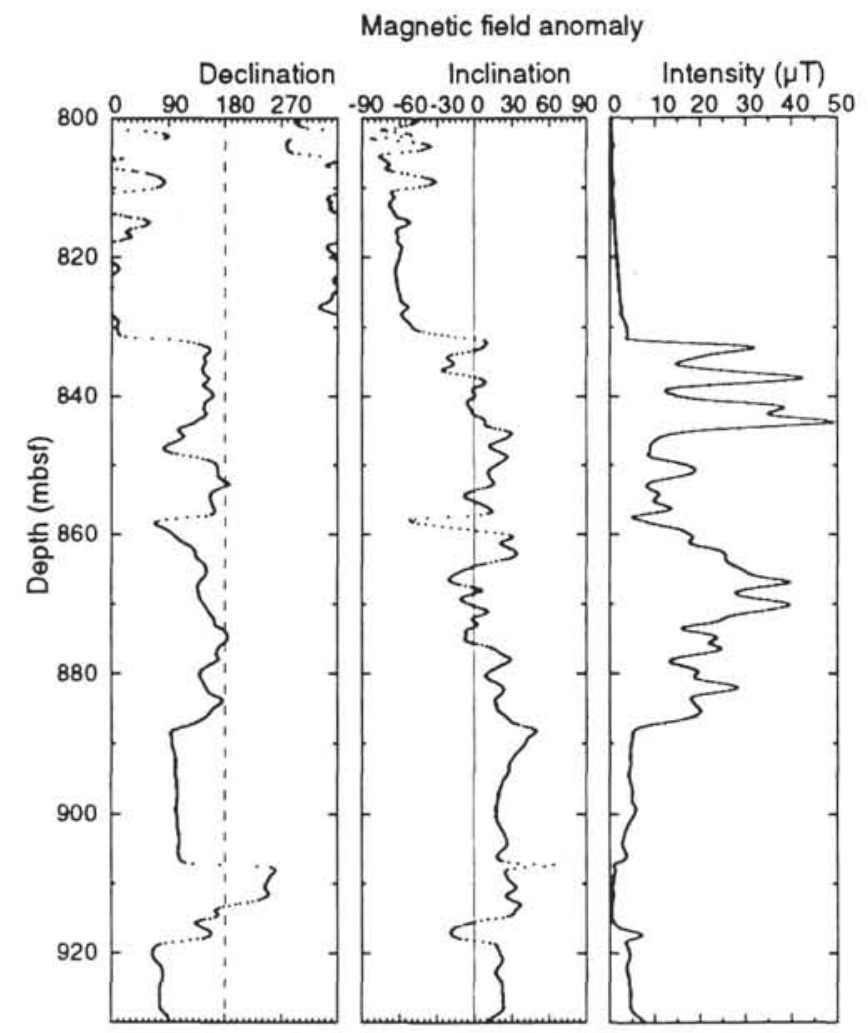

Figure 18. Magnetic field anomaly profile after removal of the expected earth magnetic field at that site from the IGRF. 